\title{
LAURENT VERSINI, Baroque Montesquieu
}

\section{Stefania Carli}

\section{OpenEdition \\ Journals}

\section{Edizione digitale}

URL: http://journals.openedition.org/studifrancesi/33261

DOI: 10.4000/studifrancesi.33261

ISSN: 2421-5856

\section{Editore}

Rosenberg \& Sellier

\section{Edizione cartacea}

Data di pubblicazione: 1 décembre 2005

Paginazione: 645-646

ISSN: 0039-2944

\section{Notizia bibliografica digitale}

Stefania Carli, «LAURent versInI, Baroque Montesquieu», Studi Francesi [Online], 147 (XLX | III) | 2005, online dal 01 novembre 2015, consultato il 20 avril 2021. URL: http://journals.openedition.org/ studifrancesi/33261; DOI: https://doi.org/10.4000/studifrancesi.33261

Questo documento è stato generato automaticamente il 20 avril 2021.

\section{(c) (†)}

Studi Francesi è distribuita con Licenza Creative Commons Attribuzione - Non commerciale - Non opere derivate 4.0 Internazionale. 


\title{
LAURENT VERSINI, Baroque Montesquieu
}

\author{
Stefania Carli
}

\section{NOTIZIA}

LAURENT VERSINI, Baroque Montesquieu, Genève, Librairie Droz, 2004, («Bibliothèque des Lumières», n. 65), pp. 210.

1 Lo studio di Laurent Versini si prefigge di mostrare la duplicità di uno dei maggiori autori settecenteschi, mettendo in evidenza aspetti dell'esistenza e della produzione letteraria di Montesquieu che rimandano ad una visione barocca della vita e dell'arte, una visione sicuramente poco conosciuta e sino ad oggi, anche se può sembrare strano, poco esplorata. L'autore delle Lettres persanes nasconde infatti, dietro alla facciata illuminista, un carattere propenso ai paradossi e alle esagerazioni, agli estremi e ai colpi di genio che lo avvicinano alla cultura del primo Seicento.

2 Per meglio comprendere l'opera di Montesquieu, Versini prende innanzitutto in considerazione la personalità stessa dell'autore. Lo studioso ne analizza l'aspetto libertino: da sempre giudicato un uomo razionale e controllato, Versini pone in evidenza il carattere passionale e volubile di Montesquieu, sottolineando le sue numerose relazioni. L'autore dell'Esprit des lois viene inoltre dipinto come un uomo legato ai piaceri della vita, in particolare a quelli della tavola e del gioco d'azzardo. Questi vizi "baroques", così come sono definiti da Versini, allontanano Montesquieu dall'immagine rigida e contenuta che lo ha contraddistinto per secoli. Questo non basta però ad etichettare l'autore come un ateo epicureo unicamente votato alla soddisfazione delle proprie passioni, porta piuttosto ad indicarlo come un uomo capace di dividersi tra la devozione e le consolazioni offerte dai piccoli vizi.

3 La frequentazione di Madame de Lambert introduce Montesquieu in un milieu moderne. Il cosiddetto "lambertinage", vale a dire quella sorta di ricercatezza "du vocabulaire au service de la science et du coeur" influisce sullo stile dell'autore. Il "lambertinage" si traduce per lui in una sorta di écriture frammentata e spezzettata che molto si avvicina alla scrittura barocca. Questo stile si avverte soprattutto nelle Lettres persanes, 
dettagliatamente analizzate da Versini che arricchisce il suo studio con numerosi esempi e citazioni. La sorpresa, il contrasto, lo spirito di contraddizione, il gusto per il paradosso e le continue opposizioni sembrano costituire la base stessa di questo testo.

4 La formazione barocca di Montesquieu trapela anche dai suoi interessi artistici: l'autore è soprattutto attento a tutto ciò che è considerato bizzarro e sorprendente. Il gusto per l'estetica barocca è chiaramente espresso nelle Pensées. In esse spicca in particolar la passione per l'Italia, per Roma, per Michelangelo, per i modelli musicali italiani che attraggono l'autore per la loro vivacità e varietà. Anche la concezione che egli ha della storia viene considerata da Versini come tipicamente barocca, allontanando Montesquieu dall'idea conservatrice che egli ha sempre dato di sé. Nelle Considérations e nell'Esprit des lois, l'autore esalta con forza i bruschi ed improvvisi cambiamenti che hanno contraddistinto i secoli passati, ammirando soprattutto i Romani, popolo in grado di fornire un valido esempio da seguire, in particolar per quanto concerne la politica interna.

5 Versini individua poi un'altra conferma della vicinanza di Montesquieu allo spirito barocco nell'interesse che egli dimostra per uno dei maggiori pensatori seicenteschi: Descartes. Anche se non si può certo definire l'autore delle Lettres persanes come un cartesiano rigido e particolarmente devoto, l'attenzione che egli rivolge al suo predecessore attesta la forza di un pensiero spesso indirizzato verso il secolo precedente piuttosto che verso l'epoca illuministica.

6 Al contrario di quanto affermato da Jean Starobinski, Montesquieu non è dunque l'uomo del "juste milieu", né tanto meno della monotonia e dell'uguaglianza. Il mondo che egli descrive nelle sue opere è in continuo movimento, ricco di violenze e di atrocità, tutti elementi che lo riallacciano ad una visione esistenziale barocca. Ciò appare particolarmente evidente nelle Lettres persanes dove dominano temi tipicamente seicenteschi: vi si trovano infatti continuamente "Du sang, de la volupté, de la mort", che sembrano attirare l'autore. La varietà e la sorpresa rendono a volte difficile individuare un filo conduttore coerente all'interno dei suoi testi. E'quello che accade, per esempio, nell'Esprit des lois, opera nella quale il continuo salto da un argomento all'altro rende complicato il reperimento di una logica nella distribuzione dei vari temi. Questo non significa accusare l'autore di incoerenza; la varietà dello stile e dei soggetti da lui affrontati permettono anzi di valorizzare il suo spiccato gusto per l'intuizione e la novità.

7 A duecentocinquant'anni di distanza dalla morte di Montesquieu, lo studio di Versini consente di avvicinarsi ad uno dei maggiori esponenti del Settecento illuminista francese in maniera del tutto nuova. Dall'analisi condotta da Versini affiora un Montesquieu completamente rivalutato e alquanto diverso da quello che si conosceva. Il mondo che egli descrive nelle sue opere è fatto di ombre in cui regnano l'illusione, la menzogna, le maschere, i miraggi, i faux-semblants, il trompe-l'oeil, i fantasmi e i demoni tipici dell'estetica barocca: essi permettono di scoprire la doppia personalità dell'autore, nel cui carattere, accanto alla ragione, alla moderazione e alla riflessione, spiccano la passione, il gusto per l'estremo e i colpi di genio improvvisi. 